Research Article

Tao Meng*, Sara Ahmed, Dawang Dai, and Yue Yu

\title{
Effects of load types and critical molar ratios on strength properties and geopolymerization mechanism
}

https://doi.org/10.1515/rams-2021-0019

Received Dec 13, 2020; accepted Dec 23, 2020

Abstract: In this study, the effect of $\mathrm{SiO}_{2} / \mathrm{Al}_{2} \mathrm{O}_{3}(\mathrm{~S} / \mathrm{A})$, $\mathrm{Na}_{2} \mathrm{O} / \mathrm{Al}_{2} \mathrm{O}_{3}(\mathrm{~N} / \mathrm{A})$ and $\mathrm{H}_{2} \mathrm{O} / \mathrm{Na}_{2} \mathrm{O}(\mathrm{H} / \mathrm{N})$ molar ratios on bending and compressive strength of geopolymer were investigated. The geopolymerization mechanism was also analyzed from microstructure difference by FTIR. The experimental results showed that compressive strength and bending strength of geopolymer has an opposite reaction under different critical molar ratios. The increase of $\mathrm{S} / \mathrm{A}$ molar ratio and the decrease of $\mathrm{N} / \mathrm{A}$ and $\mathrm{H} / \mathrm{N}$ molar ratios have resulted in an increase of the compressive strength. However, it caused a noticeable decrease in bending strength. The microstructure of geopolymer indicated that the degree of polymerization and cohesion of geopolymer have systematical depending on these critical molar ratios, making the mechanical properties of geopolymer susceptible to different types of loads. This paper reveals the relationship between the microstructure of geopolymer and different mechanical properties and helps to selectively prepare corresponding geopolymer for different loading patterns.

Keywords: geopolymer, critical molar ratio, load type, strength properties, mechanism

\section{Introduction}

Geopolymer is a kind of calcium-free inorganic silicaalumina cementitious materials, which involves the chemical reaction of alumino-silicate oxides with alkali polysil-

\footnotetext{
^Corresponding Author: Tao Meng: College of Civil Engineering and Architecture, Zhejiang University, Hangzhou 310058, China; Email: taomeng@zju.edu.cn

Sara Ahmed, Dawang Dai: College of Civil Engineering and Architecture, Zhejiang University, Hangzhou 310058, China Yue Yu: College of Civil Engineering and Architecture, Zhejiang University, Hangzhou 310058, China; Hangzhou Branch of Urban Planning \& Architectural Design Institute of Fudan University, Hangzhou 310056, China
}

icates yielding polymeric $\mathrm{Si}-\mathrm{O}-\mathrm{Al}$ bonds at temperatures lower than $100^{\circ} \mathrm{C}$ or even at room temperature $[1,2]$. It presents the properties of fast hardening [3], high earlystrength [4], good mechanical properties [5, 6], hightemperature resistance [7] and a good immobilization system for heavy metals [8]. Recent research showed that the synthesis from industrial wastes and modification by nanotechnology have attracted close attention in the world [919].

Davidovits et al. [1] proposed that the amorphous to semi-crystalline three-dimensional silico-aluminate structures, the products of polymerization reaction, are of the Poly(sialate) type, the Poly(sialate-siloxo) type, the Poly(sialate-disiloxo) type, whose formation has important connections with $\mathrm{S} / \mathrm{Al}, \mathrm{Na} / \mathrm{Al}$ and $\mathrm{H} / \mathrm{Na}$ molar ratios [9]. A lot of researches show that mechanical properties of geopolymer are also related to these three molar ratios. Duxson et al. [20, 21] studied effects of $\mathrm{Si} / \mathrm{Al}$ and $\mathrm{Na} / \mathrm{K}$ on the microstructure and mechanical properties of geopolymer and found that as $\mathrm{Si} / \mathrm{Al}$ increased, compressive strength and Young's modulus increased and then decreased, and reached the maximum when $\mathrm{Si} / \mathrm{Al}$ reached 1.90 and $\mathrm{Na} / \mathrm{K}$ was $0.5 / 0.5$. He et al. [22] found that as the $\mathrm{Si} / \mathrm{Al}$ increased from 2 to 4, the molecular structure also changed, resulting in a gradual increase in flexural strength and Young's modulus. Fletcher et al. [23] studied the microstructure and mechanical properties of geopolymer, when $\mathrm{Si} / \mathrm{Al}$ changed from 0.5 to 300, and found that when $\mathrm{Si} / \mathrm{Al}$ was greater than 24, no brittle failure occurred in the compressive specimens, and ductility gradually increased. Zhang et al. [24] studied the effect of $\mathrm{Na}_{2} \mathrm{O} / \mathrm{Al}_{2} \mathrm{O}_{3}$ and $\mathrm{H}_{2} \mathrm{O} / \mathrm{Na}_{2} \mathrm{O}$ molar ratios on the preparation of PSDS geopolymer and found that the maximum compressive strength was $34.9 \mathrm{MPa}$, when $\mathrm{SiO}_{2} / \mathrm{Al}_{2} \mathrm{O}_{3}$ $=5.5, \mathrm{Na}_{2} \mathrm{O} / \mathrm{Al}_{2} \mathrm{O}_{3}=1.0, \mathrm{H}_{2} \mathrm{O} / \mathrm{Na}_{2} \mathrm{O}=7.0$. Khan et al. [25] studied the effect of $\mathrm{Na} / \mathrm{Al}$ molar ratio and water-solid ratio on geopolymer adhesion, setting time, microstructure and temperature stability. Yusuf et al. [26] studied the effect of $\mathrm{H}_{2} \mathrm{O} / \mathrm{Na}_{2} \mathrm{O}$ molar ratio on microstructure and mechanical properties of geopolymer. It was found that High $\mathrm{H}_{2} \mathrm{O} / \mathrm{Na}_{2} \mathrm{O}$ had a negative effect on the degree of polymerization thereby leading to low compressive strength due

๑ Open Access. (C) 2021 T. Meng et al., published by De Gruyter. (cc) BY This work is licensed under the Creative Commons Attribution 4.0 License 
Table 1: Chemical composition of raw materials

\begin{tabular}{cccccc}
\hline Raw materials & $\mathrm{Al}_{2} \mathrm{O}_{3}$ & $\mathrm{SiO}_{2}$ & $\mathrm{Na}_{2} \mathrm{O}$ & $\mathrm{H}_{2} \mathrm{O}$ & others \\
\hline Water glass & $0.00 \%$ & $27.35 \%$ & $8.42 \%$ & $64.23 \%$ & $0.00 \%$ \\
Metakaolin & $32.60 \%$ & $59.72 \%$ & $0.00 \%$ & $0.00 \%$ & $7.68 \%$ \\
\hline
\end{tabular}

to the presence of excessive pores and microcracks within the matrix. Zhang et al. [27] studied the reaction kinetics, phase formation and mechanical properties of metakaolinbased geopolymer by varying $\mathrm{Si} / \mathrm{Al}$ molar ratios of 1.2-2.2 and $\mathrm{Na} / \mathrm{Al}$ molar ratios of 0.6-1.2.

In view of the microstructure of geopolymer, researchers used XRD $\backslash$ SEM and other microscopic techniques to study it. Duan et al. [28]. investigated durability and microstructure of fly ash and metakaolin based geopolymer, they concluded that geopolymer presented better durability and denser microstructure compared to ordinary Portland cement when exposed to elevated temperatures and acid attack. Subaer et al. [29]. investigated the structure of the geopolymer using XRD. The XRD patterns revealed that Na-PS geopolymer consists of zeolite-X in conjunction with amorphous aluminosilicate, while Na-PSS geopolymer was amorphous with a broad hump in the region $20^{\circ}-38^{\circ}(2 \theta)$. Duan et al. [30] investigated the effects of silica fume on properties of fly ash based geopolymer under thermal cycles. They concluded that the incorporation of silica fume optimizes the microstructure and improves the thermal resistance of geopolymer and the pores of geopolymer are also refined by the addition of silica fume. From the above results, as a new gel material, the microstructure analysis of geopolymers has yet to be further revealed.

Lots of studies have shown that $\mathrm{Si}_{2} \mathrm{O} / \mathrm{Al}_{2} \mathrm{O}_{3}$, $\mathrm{Na}_{2} \mathrm{O} / \mathrm{Al}_{2} \mathrm{O}_{3}$ and $\mathrm{H}_{2} \mathrm{O} / \mathrm{Na}_{2} \mathrm{O}$ molar ratios are the key parameters that influence the microstructure and mechanical properties of geopolymer. Most of them mainly focus on the effects of these ratios on compressive strength of geopolymer. However, researches are rare especially on effects and relationships of different load types on the mechanical properties of geopolymer. So in this paper, we prepare $\mathrm{Na}$ PSS geopolymer to study effects of different molar ratios on mechanical properties and microstructure of geopolymer and relationships between microstructure of geopolymer and different mechanical properties.
Table 2: Mix proportions

\begin{tabular}{cccc}
\hline No. & $\mathrm{SiO}_{2} / \mathrm{Al}_{2} \mathrm{O}_{3}$ & $\mathrm{Na}_{2} \mathrm{O} / \mathrm{Al}_{2} \mathrm{O}_{3}$ & $\mathrm{H}_{2} \mathrm{O} / \mathrm{Na}_{2} \mathrm{O}$ \\
\hline 1 & 4.30 & 0.95 & 12.63 \\
2 & 4.40 & 0.95 & 12.63 \\
3 & 4.50 & 0.95 & 12.63 \\
4 & 4.30 & 1.00 & 12.63 \\
5 & 4.30 & 1.20 & 12.63 \\
6 & 4.30 & 0.95 & 13.32 \\
7 & 4.30 & 0.95 & 14.06 \\
\hline
\end{tabular}

\section{Materials and Methods}

\subsection{Raw materials}

Relatively pure powdery metakaolin (MK) from Hangzhou, Junyi Chemical Co. was selected in this study. $\mathrm{NaOH}$ with a purity of $99.8 \mathrm{wt} \%$ and sodium silicate solution (water glass) with S/A molar ratio of 3.2 and solid content of $37 \%$ were used as alkaline reagents. Chemical compositions of raw materials above are summarized in Table 1.

\subsection{Mix proportions}

Based on previous studies, the primary S/A, N/A and $\mathrm{H} / \mathrm{N}$ molar ratios were adjusted on a small scale to study the effect on mechanical properties and microstructure of geopolymer. Mix proportions are shown in detail in Table 2.

\subsection{Mixing, curing, and testing methods}

Alkaline activator was made by dissolving solid $\mathrm{NaOH}$ in a solution of water glass and water, the liquid been allowed to cool to room temperature before mixing with metakaolin. The dry metakaolin was stirred for 1 minute by an adjustable speed mixer, then the alkaline activator was added slowly and mixed for 3 minutes in low speed then stirred for 2 minutes in high shear mode. The expansion test of geopolymer paste was conducted according to cement mortar expansion test. The paste was poured in $40 \times 40 \times 160$ 
$\mathrm{mm}^{3}$ molds. The molds sealed with plastic foil to prevent loss of water and left in room temperature for 24 hours then demolded and moved to the curing room with 90 humidity and temperature and kept there until appropriate testing age.

According to Mehta and Siddique results [31], geopolymer did well in early strength and in 3-days the mix has already reached more than $90 \%$ of 28 -days strength.

\subsection{Testing methods}

\subsubsection{Bending and compressive strength}

The specimens were moved from the curing room and wiped by dried towel after curing for the specific ages. Three specimens for flexural strength and six specimens for compressive strength of each group were tested according to JGJ/T233-2011 [32].

\subsubsection{FTIR test}

Samples dried for $24 \mathrm{~h}$, ground and sieved to pass sieve No. $0.3 \mathrm{~mm}$. Then they were mixed with $\mathrm{KBr}$ (inert and does not show absorbance for radiation) to get better resolution for peaks. AVATAR370 machine was used to performed FTIR test. The resolving power is $4 \mathrm{~cm}^{-1}$, and the scanning frequency is 32 times with a wavelength of $450-4000 \mathrm{~cm}^{-1}$. Samples were tested using attenuated total reflectance.

\subsubsection{NMR-MAS test}

The specimens were kept at $20^{\circ} \mathrm{C}$, and the hydration was stopped by pure alcohol. Before the test, the specimens were broken and ground on a $45 \mathrm{~mm}$ sieve to a residue ratio of less than $2 \%$. The NMR-MAS were performed by using Avance III HD Solid state nuclear magnetic resonance spectrometer. Cross polarization was used for ${ }^{29} \mathrm{Si}$ and one pulse was used for ${ }^{27} \mathrm{Al}$.

\section{Results and discussion}

\subsection{Effects of critical molar ratios on mechanical properties of geopolymer}

Figure 1 showed the effect of the S/A, N/A and H/Na molar ratios on bending strength, compressive strength and expansion degree of geopolymer. In Figure 1(a) samples elaborated with varied ratios of S/A and fixed N/A and H/N ratios showed better results in expansion degree of geopolymer paste. Duxson et al. mentioned that developing of S/A molar ratio has a progressive effect on the tetrahedral aluminosilicate network strength, as the strength of Si-O-Si bond is stronger than $\mathrm{Si}-\mathrm{O}-\mathrm{Al}$ and $\mathrm{Al}-\mathrm{O}-\mathrm{Al}$ [21]. Furthermore, the rise of S/A ratio from 4.30 to 4.40 and 4.50 increased the fluidity resulting in a gradual reduction of bending strength for hardened geopolymer by $23 \%$ and $43 \%$, while the com-

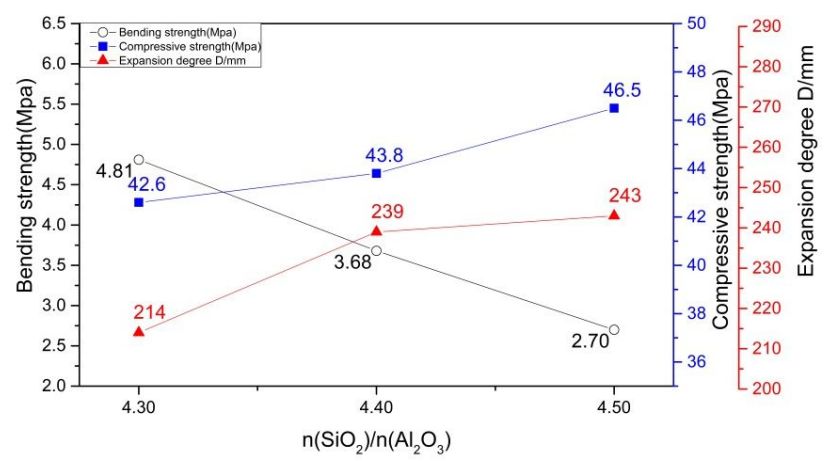

(a)

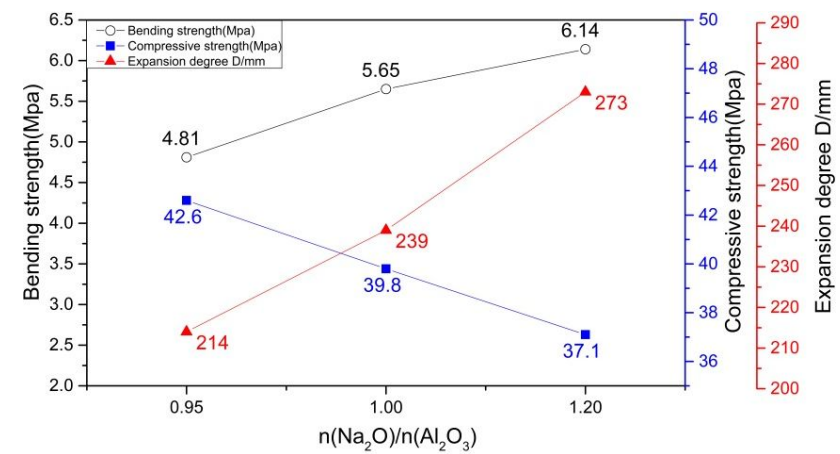

(b)

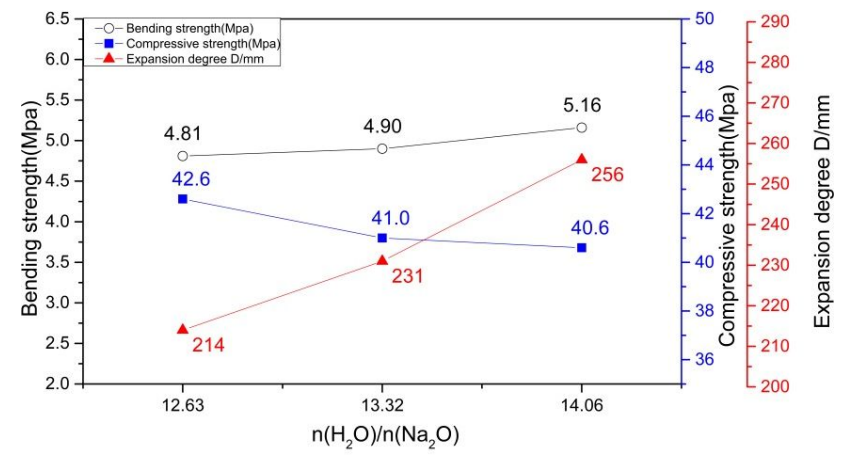

(c)

Figure 1: Effect of different molar ratios (a) S/A, (b) N/A and (c) H/N on Bending strength, compressive strength and expansion degree of geopolymer 
pressive strength increased by $3 \%$ and $9 \%$ for S/A 4.40 and 4.50 ratios respectively.

With fixed S/A and $\mathrm{H} / \mathrm{N}$ molar ratios, as N/A molar ratio varies from 0.95 to 1.00 and 1.20 , the fluidity increased, that lead to a gradual increase for the expansion degree of the geopolymer paste and bending strength of hardened geopolymer, while the compressive strength showed a dropping trend, Figure 1(b). For N/A molar ratio 1.00 the bending strength increased by $17 \%$ and compressive strength decreases by $6.5 \%$ compared to N/A 0.95 . Other samples with N/A molar ratio 1.2 followed the same behavior where the bending strength increased by $27 \%$ and compressive strength decreases by $13 \%$.

Figure 1(c) represents the effect of changing $\mathrm{H} / \mathrm{N}$ molar ratio from 12.63 to 13.32 and 14.06 for the same $\mathrm{Si}_{2} \mathrm{O} / \mathrm{Al}_{2} \mathrm{O}_{3}$ and $\mathrm{Na}_{2} \mathrm{O} / \mathrm{Al}_{2} \mathrm{O}_{3}$ molar ratios. As the $\mathrm{H} / \mathrm{N}$ increased each of the fluidity, expansion degree and bending strength increased except the compressive strength which decreased by $4 \%$ and $5 \%$ for $\mathrm{H} / \mathrm{N} 13.32$ and 14.06 respectively. The bending strength values rose by $2 \%$ and $7 \%$.

\subsection{FTIR analysis}

FTIR absorption spectroscopy is well known for its sensitivity in characterizing materials with short-range structural order and has been useful for characterizing geopolymer. Figure 2 shows the main adsorption bands of geopolymer for different S/A, N/A and H/N molar ratios. The stretching vibration of $\mathrm{O}-\mathrm{H}$ bond at 1645 and $3448 \mathrm{~cm}^{-1}$ beside the asymmetric stretching vibration (T-O-Si) at about 1020 $\mathrm{cm}^{-1}$ are related to non-solubilized particles where $\mathrm{T}=$ $\mathrm{Si}$ or $\mathrm{Al}$, symmetric stretching vibration of $\mathrm{CO}_{2}$ at about $873 \mathrm{~cm}^{-1}$, symmetrically stretching vibration of Si-O at 698 $\mathrm{cm}^{-1}$, bending vibration of Si-O-Al at $578 \mathrm{~cm}^{-1}$ and in-plane bending vibration of $\mathrm{Si}-\mathrm{O}-\mathrm{Si}$ and $\mathrm{O}-\mathrm{Si}-\mathrm{O}$ at $453 \mathrm{~cm}^{-1}$ respectively as in Figure 2(b) [33-35].

As per Figure 2(a), the stretching vibration is extremely sensitive to $\mathrm{Si} / \mathrm{Al}$ composition ratio in structure for that by increasing the S/A ratio from 4.3 to 4.5 the corresponding peak may shift to lower frequency due to the more Si substitution by $\mathrm{Al}$ in IV fold coordination, which indicates that the partial replacement of $\mathrm{SiO}_{4}$ species by $\mathrm{AlO}_{4}$ will result in a change in the local chemical environment of $\mathrm{Si}-\mathrm{O}$ bond [21]. Si-O bond has higher bond energy than Al-O bond, leading to higher cohesion in structure, which resulted in higher compressive strength for S/A molar ratio of 4.50 than 4.30 as mentioned before. The broad bands in the region of $1645-3448 \mathrm{~cm}^{-1}$ characterized the spectrum of stretching and deformation vibrations of $\mathrm{OH}$ and $\mathrm{H}-\mathrm{O}-\mathrm{H}$ groups from weakly bound water molecules which are adsorbed on the

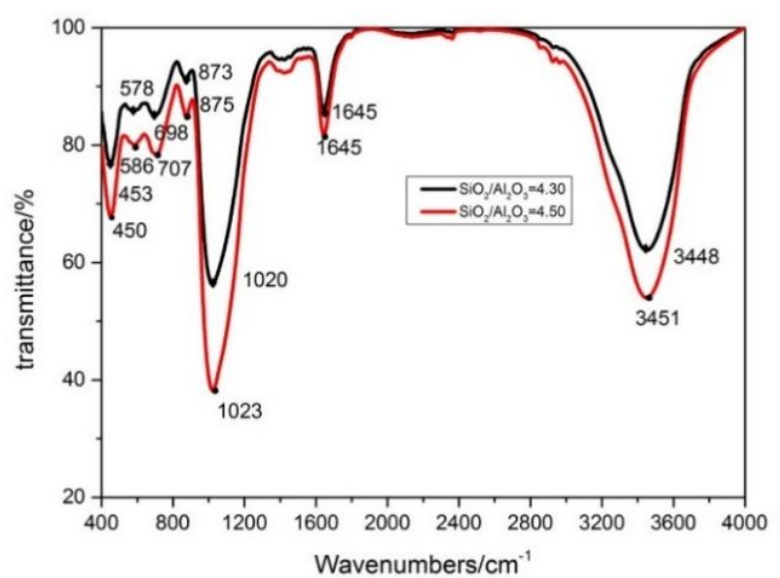

(a)

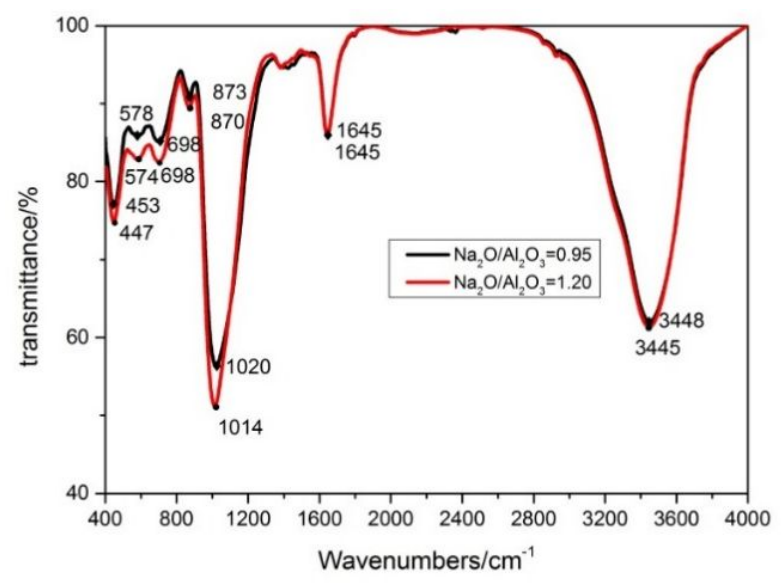

(b)

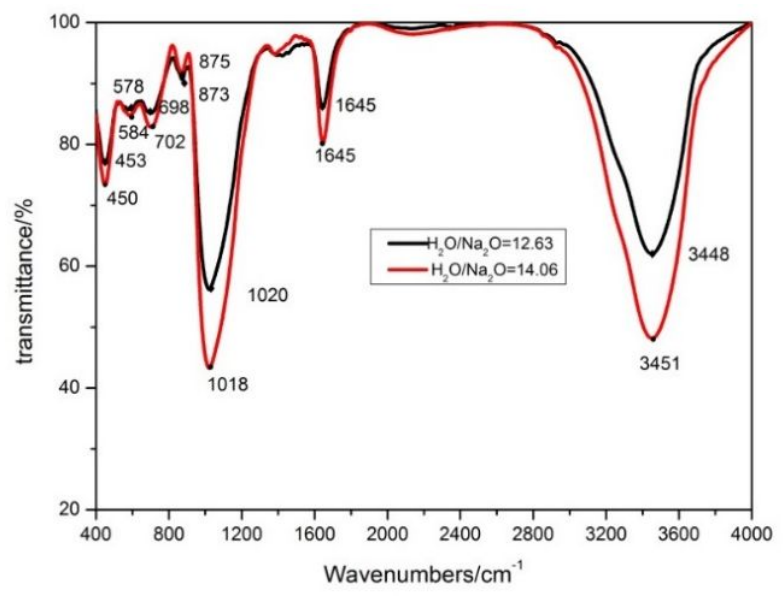

(c)

Figure 2: Fourier transform infrared spectroscopy (FTIR) of geopolymer (a) FTIR of S/A molar ratio of 4.30 and 4.50, (b) FTIR of N/A molar ratio of 0.95 and 1.20 and (c) FTIR of $\mathrm{H} / \mathrm{N}$ molar ratio of 12.63 and 14.06 
surface or trapped in the large cavities between rings of geopolymeric products [35]. So the broader bands in the region for S/A molar ratio of 4.50 than 4.30 caused more weak regions and lead to lower bending strength.

With the increase of N/A molar ratio from 0.95 to 1.20, asymmetric stretching vibration ( $\mathrm{T}-\mathrm{O}-\mathrm{Si}$ ) shifted from 1020 $\mathrm{cm}^{-1}$ to $1014 \mathrm{~cm}^{-1}$ and bending vibration of Si-O-Al shifted from $578 \mathrm{~cm}^{-1}$ to $574 \mathrm{~cm}^{-1}$ leading to the lower compressive strength of geopolymer. The vibration in the region of 900 $1300 \mathrm{~cm}^{-1}$ for N/A molar ratio of 0.95 is broader than 1.20 indicating that the increase of alkali concentration stimulated the dissolution and recombination of silicate components in raw materials so that more uniform geopolymerization products be generated, resulting in higher bending strength of geopolymer [24].

With a high $\mathrm{H} / \mathrm{N}$ molar ratio, stretching vibration ( $\mathrm{T}-$ O-Si) shifted from $1020 \mathrm{~cm}^{-1}$ to $1018 \mathrm{~cm}^{-1}$ and the region of $900-1300 \mathrm{~cm}^{-1}$ became broader leading to lower compressive strength due to the presence of excessive pores and microcracks within the matrix. At the same time, with high $\mathrm{H} / \mathrm{N}$ molar ratio, formation of more gel phase $\left[\mathrm{Na}_{x}\left(\mathrm{AlO}_{2}\right)_{y} \cdot \mathrm{nNaOH} \cdot \mathrm{mH}_{2} \mathrm{O}\right]$ made the polymerization between alkali silicate solution and aluminum-silicon complicated, contributing to the improvement of bending strength [25].

\subsection{NMR-MAS analysis}

Magic Angle Spectroscopy Nuclear Magnetic Resonance (MAS NMR) is an important microscopic technique for studying Si-Al structures, which can provide effective structural data for the study of geopolymers, especially MAS

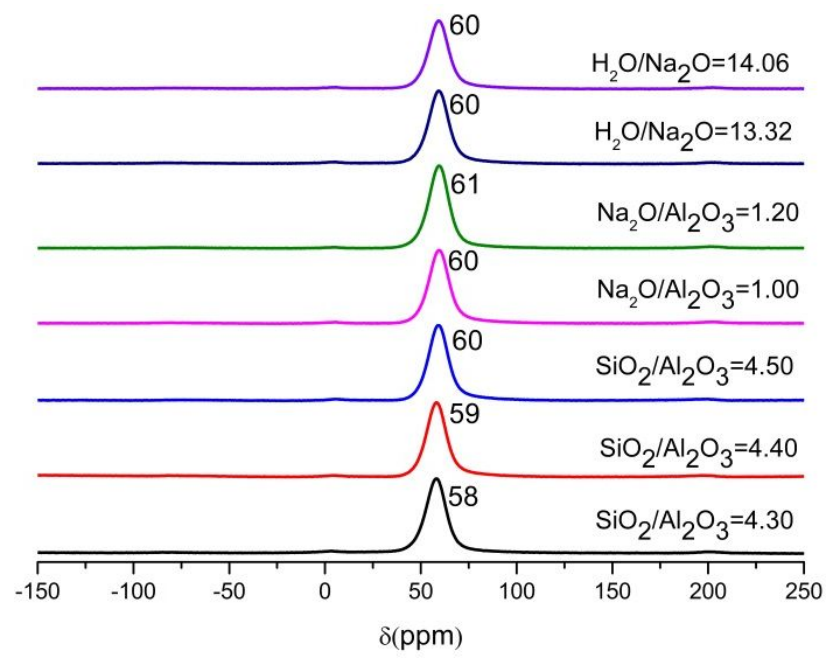

Figure 3: ${ }^{27} \mathrm{Al}$ MAS NMR results of geopolymers
NMR of ${ }^{29} \mathrm{Si}$ and ${ }^{27} \mathrm{Al} .{ }^{27} \mathrm{Al}$ MAS NMR can determine the coordination number of aluminum atoms in geopolymer and the corresponding basic unit, but cannot distinguish whether the geopolymer unit is PS type, PSS type or PSDS type, which requires ${ }^{29} \mathrm{Si}$ MAS NMR. Studies have shown that the chemical shift of ${ }^{29} \mathrm{Si}$ increases with the degree of polycondensation of the silicon tetrahedron, and with each alum tetrahedron connecting to silicon tetrahedron, the chemical shift of ${ }^{29} \mathrm{Si}$ increases by about $5 \mathrm{ppm}$. Therefore,

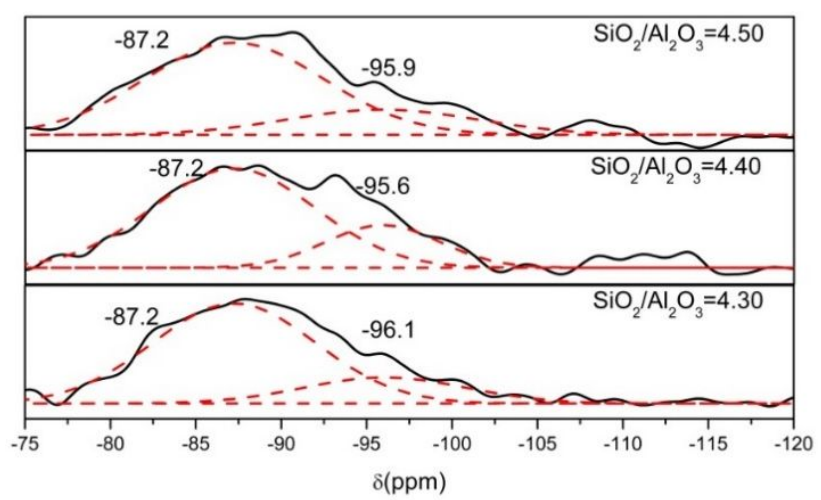

(a)

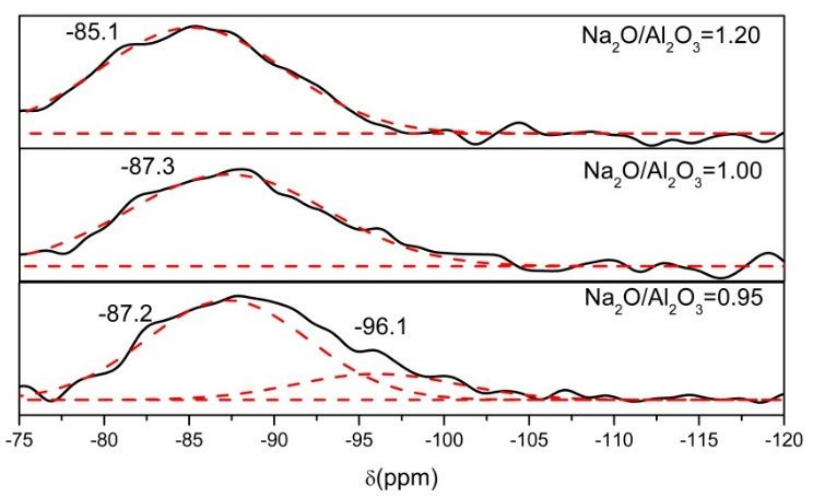

(b)

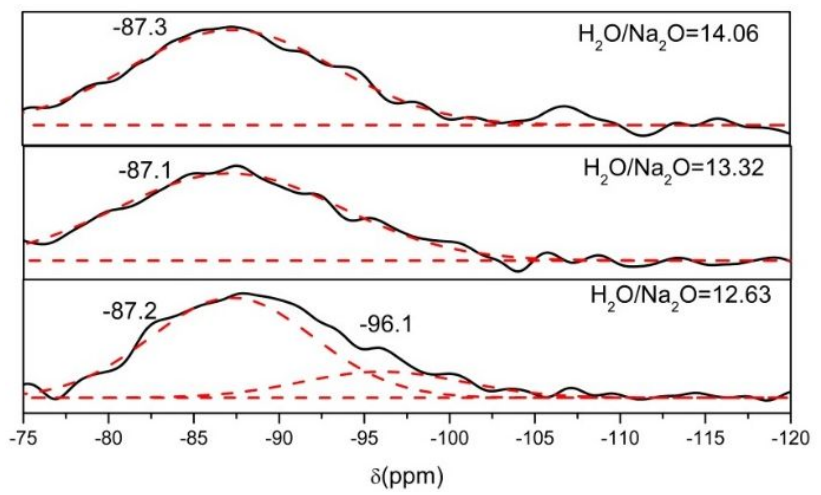

(c)

Figure 4: ${ }^{29} \mathrm{Si}$ MAS NMR spectrum of geopolymer with different molar ratios 
${ }^{29}$ Si MAS NMR can be used to determine the structure and dynamics of geopolymer systems.

The ${ }^{27} \mathrm{Al}$ MAS NMR results of geopolymers in Figure 3 showed that molar ratios had some influence on geopolymer structure. The extremely narrow peak at 58-61 ppm indicated a well-defined single $\mathrm{Al}$ environment which exists in the form of tetrahedral $\mathrm{Al} \mathrm{Q}_{4}(4 \mathrm{Si})$, and there were no low relative molecular mass like dimers and trimers in geopolymer structure, which mean geopolymer was a kind of silicon-aluminum compounds with spatial threedimensional networks.

${ }^{29} \mathrm{Si}$ MAS NMR spectrum showed a broad resonance between $-75 \mathrm{ppm}$ and $-120 \mathrm{ppm}$ associated with very strong resonance at about $-87 \mathrm{ppm}$ and a small peak at about -96 ppm (Figure 4). Resonances in the ${ }^{29} \mathrm{Si}$ MAS NMR spectrum, namely $-85 \mathrm{ppm},-87 \mathrm{ppm}$ and $-96 \mathrm{ppm}$, can be assigned to $\mathrm{Q}_{4}(4 \mathrm{Al}), \mathrm{Q}_{4}(4 \mathrm{Al})$ and $\mathrm{Q}_{4}(3 \mathrm{Al})$ respectively. The spectrum showed that with $\mathrm{Na} / \mathrm{Al}$ ratio and $\mathrm{H} / \mathrm{Na}$ increasing, $\mathrm{Q}_{4}(3 \mathrm{Al})$ disappeared, which indicated to some degree that there were more $\mathrm{Al}$ in the geopolymer structure.

\section{Conclusions}

This paper firstly studied the effect of load type on properties of geopolymers and use FTIR and NMR to explain the reason for different development of compressive strength and bending strength of geopolymer. The detailed experimental results were shown as follows.

(1) $\mathrm{Si}_{2} \mathrm{O} / \mathrm{Al}_{2} \mathrm{O}_{3}, \mathrm{Na}_{2} \mathrm{O} / \mathrm{Al}_{2} \mathrm{O}_{3}$ and $\mathrm{H}_{2} \mathrm{O} / \mathrm{Na}_{2} \mathrm{O}$ molar ratios all had significant influence on mechanical properties and microstructure of geopolymer.

(2) The fluidity of the geopolymer can be enhanced by higher $\mathrm{Si}_{2} \mathrm{O} / \mathrm{Al}_{2} \mathrm{O}_{3}, \mathrm{Na}_{2} \mathrm{O} / \mathrm{Al}_{2} \mathrm{O}_{3}$ and $\mathrm{H}_{2} \mathrm{O} / \mathrm{Na}_{2} \mathrm{O}$ molar ratios. But $\mathrm{Si}_{2} \mathrm{O} / \mathrm{Al}_{2} \mathrm{O}_{3}, \mathrm{Na}_{2} \mathrm{O} / \mathrm{Al}_{2} \mathrm{O}_{3}$ and $\mathrm{H}_{2} \mathrm{O} / \mathrm{Na}_{2} \mathrm{O}$ molar ratios had different effects on mechanical strength with different load types. When increasing $\mathrm{Si}_{2} \mathrm{O} / \mathrm{Al}_{2} \mathrm{O}_{3}$ molar ratio or decreasing $\mathrm{Na}_{2} \mathrm{O} / \mathrm{Al}_{2} \mathrm{O}_{3}$ and $\mathrm{H}_{2} \mathrm{O} / \mathrm{Na}_{2} \mathrm{O}$ molar ratio, bending strength tended to decrease and compressive strength tended to increase.

(3) Results in the paper showed that bending strength increased while compressive strength decreased and bending strength decreased while compressive strength increased, which may be connected with the polymerization and cohesion of groups in the microstructure of geopolymer. The fluidity of fresh geopolymer was not related to the mechanical properties of geopolymer.
Acknowledgement: The authors want to thank the support by Zhejiang Key Research \& Development Program (2020C04013) and National Natural Science Foundation of China (52078453).

Funding information: This work was supported by the Zhejiang Key Research \& Development Program (2020C04013) and National Natural Science Foundation of China (52078453).

Conflict of Interests: Authors state no conflict of interest.

\section{References}

[1] Davidovits, J., Geopolymers: Inorganic polymeric new materials. Journal of Thermal Analysis and Calorimetry. Vol. 37, No. 8, 1991, pp. 1633-1656.

[2] Subaer., N. Amalia, Nurfadilla, A. Riska, Sulfiana, F. P. San, et al. The Potential of laterite soils deposit South Sulawesi as a precursor for Na-poly (ferro-sialate) geopolymers. Matec Web of Conferences, Vol. 97, 2016, 01014.

[3] Yaseri, S., G. Hajiaghaei, F. Mohammadi, Mandikhani, Mandi, R. Farokhzad. The role of synthesis parameters on the workability, setting and strength properties of binary binder based geopolymer paste. Construction and Building Materials, Vol. 157, No. 30, 2017, pp. 534-545.

[4] Yip, C. K., G. C. Lukey, and J. S. J. V. Deventer. The coexistence of geopolymeric gel and calcium silicate hydrate at the early stage of alkaline activation. Cement and Concrete Research, Vol. 35, No. 9,2005, pp. 1688-1697.

[5] Guo. X., H. Shi, and W. A. Dick. Compressive strength and microstructural characteristics of class $\mathrm{C}$ fly ash geopolymer. $\mathrm{Ce}$ ment \& Concrete Composites, Vol. 32, No. 2, 2010, pp. 142-147.

[6] Rashad. A. M. Metakaolin: Fresh properties and optimum content for mechanical strength in traditional cementitious materials - A comprehensive overview. Reviews on Advanced Materials Science, Vol. 40, No. 2, 2015, pp, 15-44.

[7] Kong. D. L. Y., J. G. Sanjayan, and K. Sagoe-Crentsil. Comparative Performance of Geopolymers Made with Metakaolin and Fly Ash After Exposure to Elevated Temperatures. Cement and Concrete Research, Vol. 37, No. 12, 2007, pp. 1583-1589.

[8] Guo. B., D. Pan, B. Liu, A. A. Volinsky, M. Fincan, J. Du, et al. Immobilization mechanism of $\mathrm{Pb}$ in fly ash-based geopolymer. Construction and Building Materials, Vol. 134, No. 1, 2017, pp. 123-130.

[9] Ahmed. S., T. Meng, and M. Taha. Utilization of red mud for producing a high strength binder by composition optimization and nano strengthening. Nanotechnology Reviews, Vol. 9, No. 1, 2020, pp. 396-409.

[10] Liu. C., X. Huang, and Y. Y. Wu. Review on the research progress of cement-based and geopolymer materials modified by graphene and graphene oxide. Nanotechnology Reviews, Vol. 9, No. 1, 2020, pp. 155-169.

[11] Li. W., D. P. Zheng, S. P. Zhang, and H. Cai. Effect of Nano-SiO on the Hydration and Microstructure of Portland Cement. Nano- 
materials, Vol. 6, No. 12, 2016.

[12] Meng. T., J. Zhang , H. Wei, and J. Shen. Effect of nanostrengthening on the properties and microstructure of recycled concrete. Nanotechnology Reviews, Vol. 9, No. 1, 2020, pp. 79-92.

[13] Zhuang. C. and Y. Chen. The effect of nano- $\mathrm{SiO}_{2}$ on concrete properties: A review. Nanotechnology Reviews, Vol. 8, No.1, 2019, pp. 562-572.

[14] Meng. T., K. J. Ying, Y. P. Hong, and Q. L. Xu. Effect of different particle sizes of nano- $\mathrm{SiO}_{2}$ on the properties and microstructure of cement paste. Nanotechnology Reviews, Vol. 9, 2020, pp. 833442.

[15] Kawashima. S., P. Hou, D. J. Corr,S. P. Shah. Modification of cement-based materials with nanoparticles. Cement \& Concrete Composites, Vol. 36, No. 1, 2016, pp. 8-15.

[16] Madani. H., A. Bagheri, T. Parhizkar, and A. Raisghasemi. Chloride penetration and electrical resistivity of concretes containing Nanosilica hydrosols with different specific surface areas. $\mathrm{Ce}$ ment and Concrete Composites, Vol. 53, 2014, pp. 18-24.

[17] Meng. T., J. L. Zhang, H. D. Wei, and J. J. Shen. Effect of nanostrengthening on the properties and microstructure of recycled concrete. Nanotechnology Reviews, Vol. 9, No.1, 2020, pp. 7992.

[18] Rashad. A. M. A synopsis about the effect of nano-titanium dioxide on some properties of cementitious materials - A short guide for civil engineer. Reviews on Advanced Materials Science, Vol. 40, No. 1, 2015, pp. 72-88.

[19] Hu. Y. S., Z. Y. Yu, and G. L. Fan. Simultaneous enhancement of strength and ductility with nano dispersoids in nano and ultrafine grain metals: a brief review. Reviews on Advanced Materials Science, Vol. 59, No. 1, 2020, pp. 352-360.

[20] Duxson P., Mallicoat S. W., Lukey G. C., et al. The effect of alkali and $\mathrm{Si} / \mathrm{Al}$ ratio on the development of mechanical properties of metakaolin-based geopolymers. Colloids \& Surfaces A, Vol. 292, No. 1, pp. 8-20.

[21] Duxson. P., J. L. Provis, G. C. Lukey, W. M. Kriven, and J. S. J. V. Deventer. Understanding the relationship between geopolymer composition, microstructure and mechanical properties. Colloids and Surfaces A Physicochemical \& Engineering Aspects, Vol. 292, No. 1, 2005, pp. 47-58.

[22] He, P. J., M. R. Wang, S. Fu, D. C. Jia, S. Yan, J. K. Yuan, et al. Effects of $\mathrm{Si} / \mathrm{Al}$ ratio on the structure and properties of metakaolin based geopolymer. Ceramics International, Vol. 42, No.13, 2016, pp. 14416-14422.

[23] Fletcher. R. A., K. J. D. Mackenzie, and C. L. Nicholson. The Composition Range of Aluminosilicate Geopolymers. Journal of the European Ceramic Society, Vol. 25, No. 9, 2005, pp. 1471-1477.
[24] Zhang. Y. S., W Sun, and Z. J. Li. Composition design and microstructural characterization of calcined kaolin-based geopolymer cement. Applied Clay Science, Vol. 47, No.3, 2010, pp. 271275.

[25] Khan, I. M., K. Azizli, S. Sufian, and Z. Man. Sodium silicatefree geopolymers as coating materials: Effects of $\mathrm{Na} / \mathrm{Al}$ and water/solid ratios on adhesion strength. Ceramics International, Vol. 41, No. 2, 2015, pp. 2794-2805.

[26] Yusuf. M. O., M. A. M. Johari , Z. A. Ahmad, and M. Maslehuddin. Effects of $\mathrm{H}_{2} \mathrm{O} / \mathrm{Na}_{2} \mathrm{O}$ molar ratio on the strength of alkaline activated ground blast furnace slag-ultrafine palm oil fuel ash based concrete. Materials and Design, Vol. 56, 2014, pp. 158-164.

[27] Zhang. M., M. Zhao, G. Zhang, T. El-Korchi, and M. Tao. A multiscale investigation of reaction kinetics, phase formation, and mechanical properties of metakaolin geopolymers. Cement and Concrete Composites, Vol. 78, 2017, pp. 21-32.

[28] Duan. P., C. Yan, W. Zhou, W. Lou, and C. Shen. An investigation of the microstructure and durability of a fluidized bed fly ashmetakaolin geopolymer after heat and acid exposure. Materials \& design, Vol. 74, 2015, pp. 125-137.

[29] Subaer. H. A., Nurhayati, A. Lrhamsyah, and J. J. Ekaputri. The Influence of Si:Al and Na:Al on the Physical and Microstructure Characters of Geopolymers Based on Metakaolin. Materials ence Forum, Vol. 841, No. 1, 2016, pp, 170-177.

[30] Duan. P., C. J. Yan, and W. Zhou. Compressive strength and microstructure of fly ash based geopolymer blended with silica fume under thermal cycle. Cement \& concrete composites, Vol. 78, 2017, pp. 108-119.

[31] Mehta. A. and R. Siddique. Strength, permeability and microstructural characteristics of low-calcium fly ash based geopolymers. Construction and Building Materials, Vol. 141, No. 15, 2017, pp. 325-334.

[32] China National Standards JGJ/T233-2011. Specification for mix proportion design of cement soil. Beijing, China (in Chinese).

[33] Vargas. A. S. D., D. C. C. D. Molin, B. Masuero, A. C. F. Vilela, J. C. Gomes, and R. M. D. Gutierrierz. Strength development of alkaliactivated fly ash produced with combined $\mathrm{NaOH}$ and $\mathrm{Ca}(\mathrm{OH})_{2}$ activators. Cement and Concrete Composites, Vol. 53, 2014, pp. 341-349.

[34] Jaarsveld. J. G. S. V and J. S. J. V. Deventer. The effect of metal contaminants on the formation and properties of waste-based geopolymers. Cement and Concrete Research, Vol. 29, No. 8, 1999, pp. 1189-1200.

[35] Peyne. J., J. Gautron, J. Doudeau, E. Joussein, and S. Rossignol. Influence of calcium addition on calcined brick clay based geopolymers: A thermal and FTIR spectroscopy study. Construction and Building Materials, Vol. 152, No. 15, 2017, pp. 794-803. 